\title{
APPLICATION OF FRICTION STIR WELDING METHOD FOR REPAIR AND RESTORATION OF WORN-OUT COPPER PLATES OF MCCB MOULDS
}

\author{
G.M. GRIGORENKO ${ }^{1}$, L.I. ADEEVA ${ }^{1}$, A.Yu. TUNIK ${ }^{1}$, M.A. POLESHCHUK ${ }^{1}$, \\ E.V. ZELENIN ${ }^{1}$, V.I. ZELENIN ${ }^{1}$, Yu.N. NIKITYUK ${ }^{2}$ and V.A. LUKASH ${ }^{3}$ \\ ${ }^{1}$ E.O. Paton Electric Welding Institute, NASU \\ 11 Bozhenko Str., 03680, Kiev, Ukraine. E-mail: office@paton.kiev.ua \\ ${ }^{2}$ Research and Production Company «VISP Ltd» \\ 23 Moskovsky Ave., 04655, Kiev, Ukraine \\ ${ }^{3}$ V.N. Bakul Institute for Superhard Materials, NASU \\ 2 Avtozavodskaya Str., 04074, Kiev, Ukraine
}

\begin{abstract}
The advantages of friction stir welding (FSW) are well known from numerous publications. In this work it was proposed to apply FSW in restoration of sizes of copper plates of machines for continuous casting of billets (MCCB) moulds and for the further surface hardening with nickel or nickel alloys. The microstructure of characteristic zones of joints was studied. Application of FSW provides quality joints with sufficiently high mechanical properties of deposited layer. The structure of copper-copper and copper-nickel joints was studied. It was established that in formation of joints the mechanical stirring of metals plays a leading role, and their mutual diffusion affects them to a much lesser extent. Experimental investigations were laid as the basis for development of restoration technology of copper plates with nickel coating. 14 Ref., 10 Figures.
\end{abstract}

$\boldsymbol{K} \boldsymbol{e} \boldsymbol{y} \boldsymbol{w} \boldsymbol{o} \boldsymbol{r} \boldsymbol{d} \boldsymbol{s}:$ friction stir welding, restoration of copper plates, layer deposition, copper, nickel, structure of joints, working tool

Friction stir welding (FSW), developed by the British Welding Institute (TWI) as the process of joining in solid phase, is characterized by advantages which are not common to conventional methods [1-3].

Other processes of pressure welding differ from it by a method of heating, i.e. by the method of heat input into parts being welded. In FSW the kinetic energy is directly converted into heat energy, moreover generation of heat has a strictly localized character in the thin near-surface layers of metal.
Figure 1 shows installation and scheme of joining of the overlapped type of dissimilar metals using FSW method.

Researchers point out the following advantages of this process as compared to other methods of producing permanent joints [4, 5]: significant preservation of base metal properties in the join area; absence of harmful vapors and ultraviolet radiation during welding; possibility of producing defect-free welds on alloys, which during fusion welding are prone to hot cracking and porosity in weld metal; no need in application of filler material and removal of surface oxides at the edges before welding as well as slag and spat-
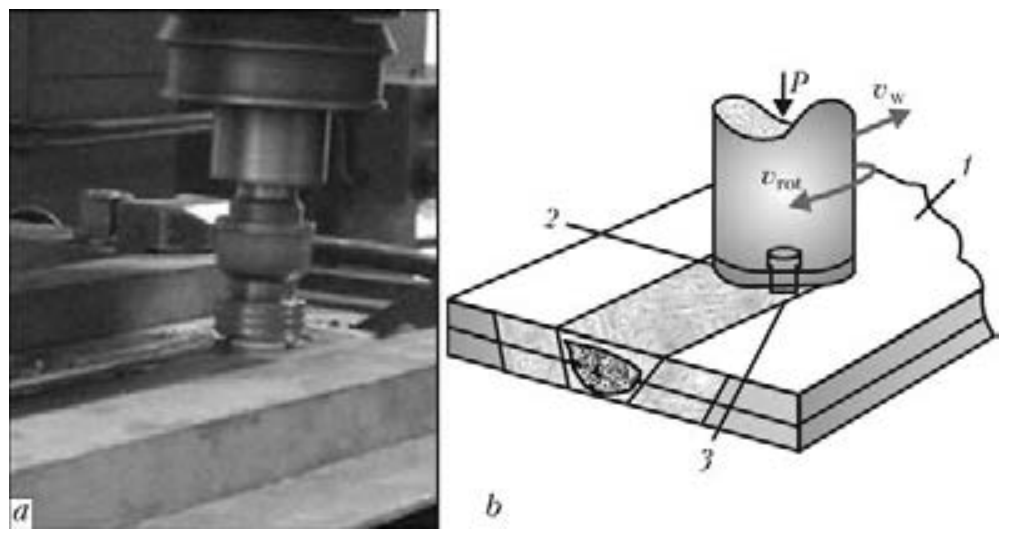

$b$

Figure 1. Installation $(a)$ and scheme of FSW process $(b): 1-$ workpiece; $2-$ shoulder; $3-$ pin tool with special profile 


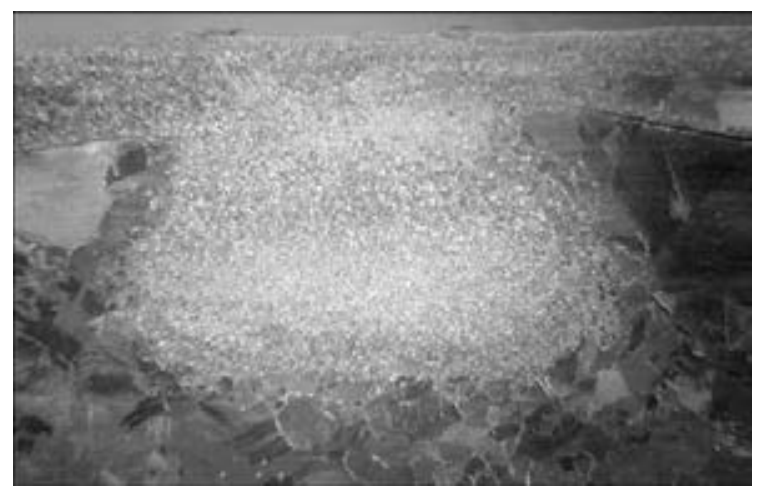

Figure 2. Macrostructure $(\times 5)$ of joint of copper layer with model object of copper of M1 grade produced using FSW

ters after welding; no losses of alloying elements in weld metal.

A great interest represents possibility of applying FSW to join similar and dissimilar metals. In [6-12] the successes in joining dissimilar metals by FSW method are demonstrated. As is shown in these works, weldability of metals is decisively influenced by metallurgical compatibility determined by mutual solubility of metals joined both in liquid as well as in solid states and also formation of brittle chemical compounds (intermetallics).

In this work, using FSW the authors produced and investigated $\mathrm{Cu}-\mathrm{Cu}$ and $\mathrm{Ni}-\mathrm{Cu}$ joints, the elements of which differ by unlimited solubility, with the purpose of using them to restore sizes of copper plates of moulds of machines for continuous casting of billets (MCCB) and their subsequent surface hardening using nickel or nickel alloys.

For the plates of MCCB moulds, a highly pure copper M1 (GOST 859-78) is used. It has a high thermal conductivity, which provides a quick formation of metal crust on the surface of casting. During movement of ingot through the mould a considerable, non-uniform abrasive wear of copper occurs in different areas. By conventional fusion methods it is difficult to restore MCCB moulds, since a high thermal conductivity of copper leads to a strong distortion and its interaction with oxygen, as a result of oxides formation, deteriorates the heat conducting properties of the mould.

The main zones of metal joints were obtained and examined. The macrostructure of base metal

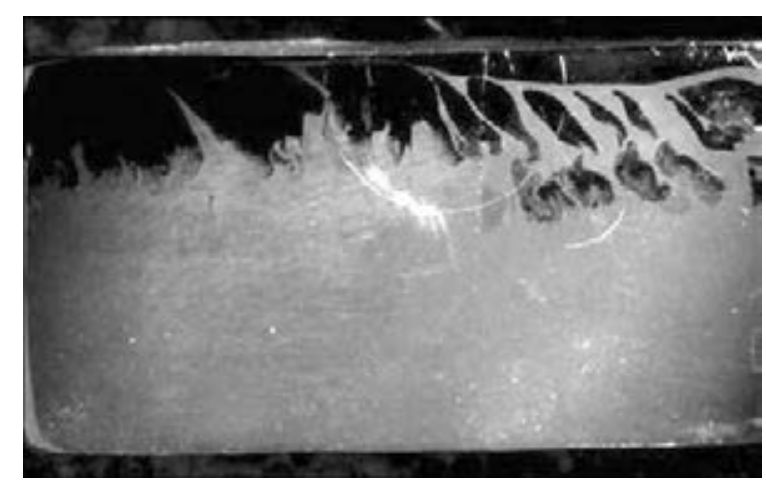

Figure 4. Microsection of copper specimen with nickel coating deposited using FSW method (optical microscope, cross section of the specimen)

with deposited layer is shown in Figure 2. As is seen from the Figure, a quality layer of metal was produced having no defects in the form of pores, cracks, or discontinuities. In the zone of dynamic recrystallization a significant grain refinement is observed. During deposition of copper on the specimen of copper MCCB mould by parallel welds a joint of somewhat different nature was formed, macrostructure of which is shown in Figure 3.

The general view of microsection of copper specimen with deposited layer of nickel is shown in Figure 4 (cross-section). Mechanical stirring of nickel and copper layers without active interaction is observed.

In the area of joining nickel and copper a mutual penetration of these metals to depth down to $3 \mathrm{~mm}$ occurs. The mass transfer of metals is marked in the form of mutually penetrating alternating bands directed towards the movement of pin tool (see Figure 4). Bands of copper and nickel have a different thickness (respectively $0.3-0.6$ and $0.03-0.30 \mathrm{~mm}$ ). Due to recrystallization the structure refinement occurs in these bands. In copper a grain size varies from 5 to 20 , and in nickel - from 5 to $40 \mu \mathrm{m}$. Microhardness of nickel bands is $1270 \pm 40$, and that of copper is $1140 \pm 50 \mathrm{MPa}$.

Using the method of electron microprobe analysis it was established that a slight diffusion of copper into nickel occurs along the grain boundaries. As a result of investigations of joints

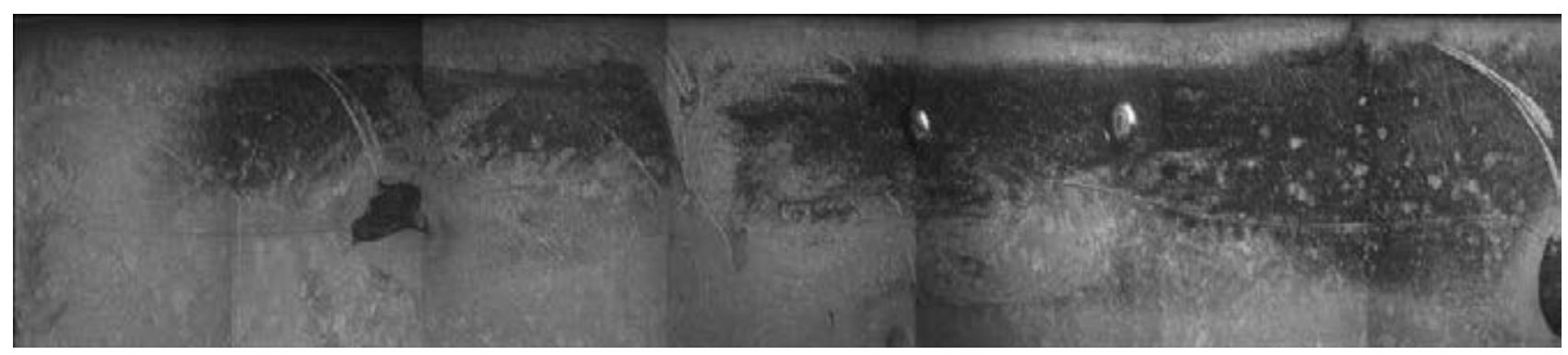

Figure 3. Macrostructure $(\times 10)$ of the M1 copper layer deposited on MCCB mould using FSW method 
of nickel with copper it was established that the mass transfer of metals plays a leading role in FSW process, and their mutual diffusion affects them to a much lesser extent.

The obtained results made it possible to develop a technology for restoration of copper moulds of continuous steel casting by deposition of surface layer of nickel and nickel-chromium coatings on them using FSW method.

In CIS since 2003 at the OJSC «Severstal» the works have been carried out on using slab moulds with slotted cooling channels [13], including those with nickel coatings. They showed their fundamental fitness and advantages over the moulds with drilling channels.

Despite the significant successes in extending the life of copper plates of MCCB moulds with coatings, the problems of their repair remain urgent even today. It was found that among the frequently encountered defects, due to which the moulds are removed from operation, is wear of sidewalls of the bottom part of cooling plates to depth of more than $2.7 \mathrm{~mm}$. Figure 5 shows picture of such a plate.

Figure 6 shows scheme of wear distribution on the working surface of narrow walls of the mould, where each line indicates increase in wear by $0.5 \mathrm{~mm}$ [13]. The presence of such defects makes their further operation unacceptable and requires replacement. The technology of repair of copper plates with the mentioned defects was developed using FSW method. Restoration of plates geometry was performed by the end of the rotating tool with protruding pin, which penetrating through a surfaced (filler) metal and moving, mixed the deposited metal with base metal [14].

To manufacture the tool for FSW a heat resistant and refractory material was selected that allowed operating at the temperatures of up to $1000^{\circ} \mathrm{C}$, at which plasticizing of copper occurs.

The procedure of restoration technology was simply enough. On the repaired segment area of the copper plate, previously milled to a certain level, copper plate of the required composition

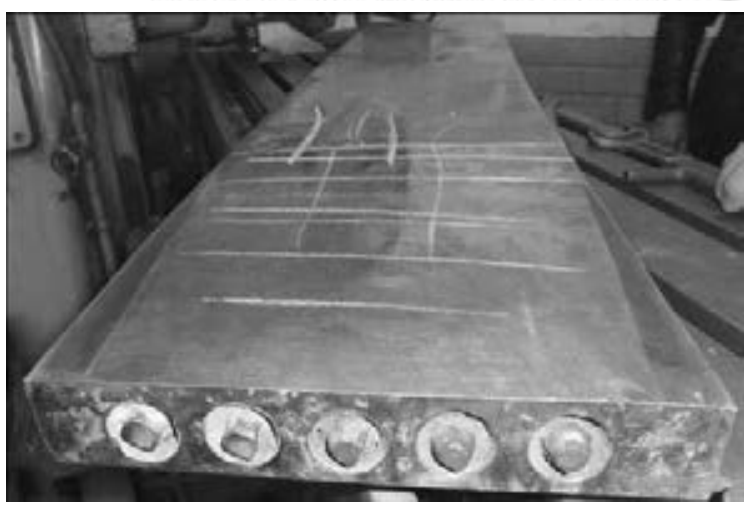

Figure 5. MCCB mould after operation

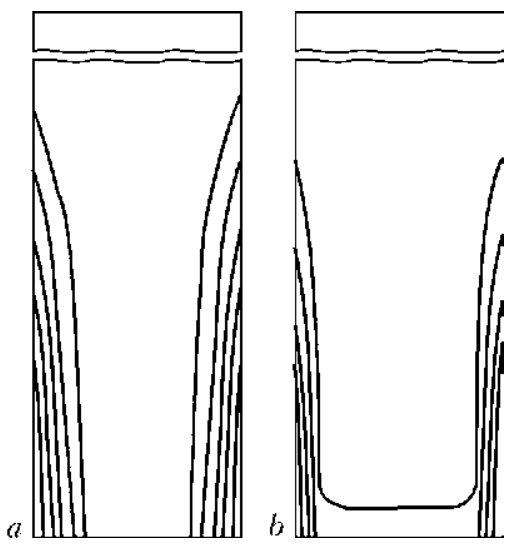

Figure 6. Distribution of wear on working surface of narrow walls of pilot ( $a$ ) and typical $(b)$ moulds (each line indicates increase of wear by $0.5 \mathrm{~mm})[13]$

and shape was placed and firmly fastened by clamps. Then rotating cylindrical tool of hard alloys with protruding pin was introduced into the plate, creating stirring of metal plate with the base metal.

Figure 7 shows steps of copper layer deposition on copper plate. It is seen that the structure of deposited layer of metal is dense, cracks, lacks of penetration and pores are absent. Metallographic examinations confirm this conclusion. Measurements of microhardness of the deposited layer of copper showed identity of its hardness of that of the restored plate. Dissolution of oxygen in the deposited layer was not observed. Similarly, when it was necessary the copper was de-
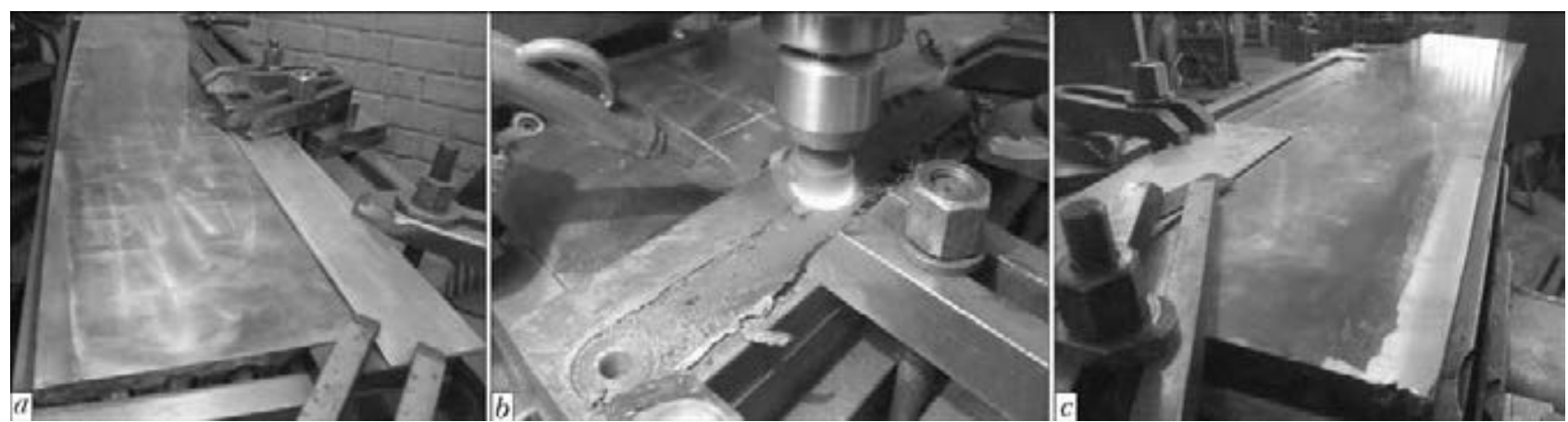

Figure 7. Stages of deposition of copper layer on copper plate: $a-$ plate with thin copper sheet; $b-$ surfacing process; $c-$ appearance of restored plate after grinding 


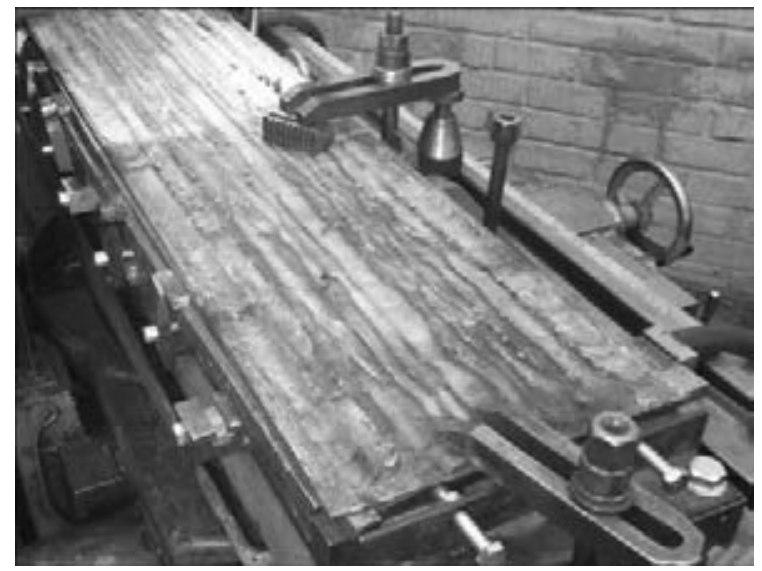

Figure 8. Layer of copper (5 mm) deposited on MCCB plate using FSW method without water cooling

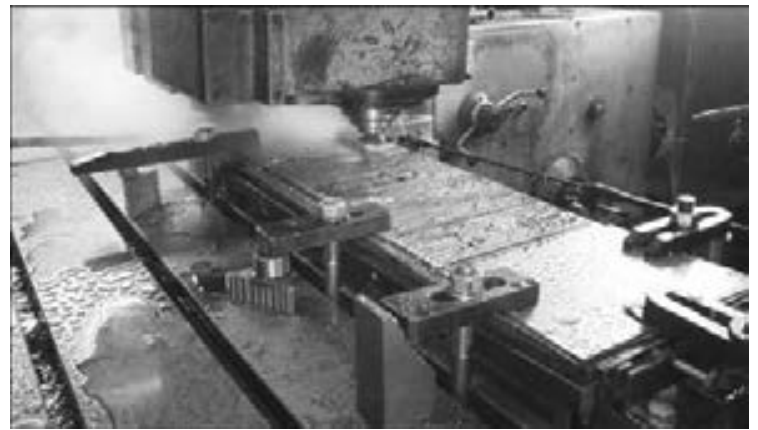

Figure 9. Process of deposition of nickel layer $(3 \mathrm{~mm})$ on copper plate of MCCB using FSW method

posited over the entire surface of the plate ( $\mathrm{Fi}$ gure 8 ). The final stage of restoration of copper plates of the mould is deposition of layer of nickel N1 $(3 \mathrm{~mm})$ using FSW method.

To deposit nickel on copper plate having a higher melting point than copper, it is needed not only to use other materials for the tool, but also to change its design. The best results are shown by hard alloys such as WK, TK and cubic boron nitride.

Such tools have increased strength and heat strength, which allows using them at the temperatures of up to $1000-1200{ }^{\circ} \mathrm{C}$. Surfacing was carried out in the installation for restoration of copper plates. To reduce oxidation of the tool, in the process of operation a cooling inert gas blowout was used (Figure 9).

After deposition of nickel the surface of MCCB plate is polished (Figure 10).

\section{Conclusions}

1. The possibility of deposition of nickel or copper layer on copper plates was shown which can be used during their restoration and strengthening to increase service life.

2. The technology of local and general repair of copper plates of MCCB moulds using FSW was developed.

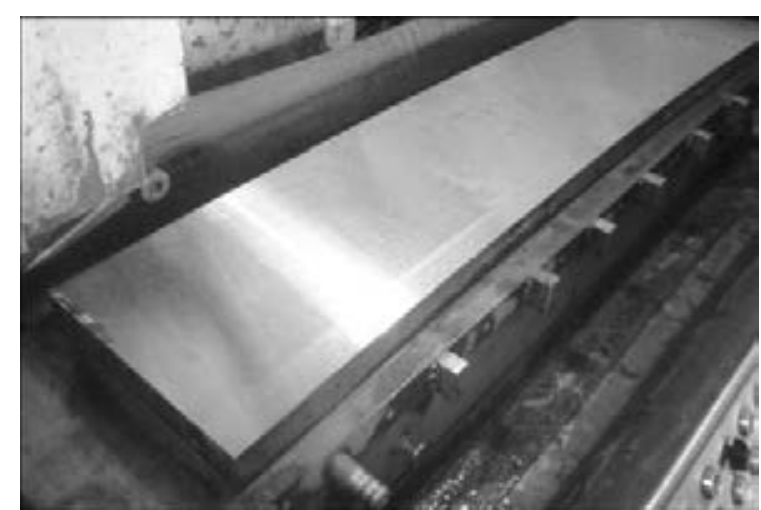

Figure 10. General view of copper plate with FSW-deposited nickel coating after grinding

3. The drawings, shape and composition of materials for the tool as-applied to FSW method were additionally modified.

4. The given technology allowed repairing defects of copper plates and depositing layers of copper and nickel.

1. Thomas, W.M. Friction stir butt welding. Pat. 9125978.8 GB. Int. Cl. PCTrGB92. Publ. 01.12.91.

2. Vill, V.I. (1970) Friction welding of metals. Leningrad: Mashinostroenie.

3. Lebedev, V.K., Chernenko, I.A., Mikhalsky, R. et al. (1987) Friction welding: Refer. Book. Leningrad: Mashinostroenie

4. Okamura, H., Aota, K., Ezumi, M. (2000) Friction stir welding of aluminum alloy and application to welded structure. J. Japan Institute of Light Metals, 50(4), 166-172.

5. Arbegast, W.J. (2006) Friction stir welding. After a decade of development. Welding J., 85(3), 28-35.

6. Watanabe, H., Takayama, H., Yanagisawa, A. (2006) Joining of aluminum alloy to steel by friction stir welding. J. Materials Proc. Techn., 178, 342-349.

7. Hirate, T., Oguri, T., Hagino, H. et al. (2007) Influence of friction stir welding parameters on grain size and formability in 5083 aluminum alloy. Materials Sci. and Eng. A, 456, 344-349.

8. Lee, W.-B., Schmuecker, M., Mercardo, U.A. et al. (2006) Interfacial reaction in steel-aluminum joints made by friction stir welding. Scripta Mater., 55, 355-358.

9. Kosta, A., Coelho, R.S., dos Santos, J. et al. (2000) Microstructure of friction stir welding of aluminium alloy to magnesium alloy. Ibid., 66, 953-956.

10. Kwon, Y.J., Shigematsu, I., Saito, N. (2008) Dissimilar friction stir welding between magnesium and aluminium alloys. Materials Letters, 62, 3827-3829.

11. Xue, P., Ni, D.R., Wang, D. et al. (2011) Effect of friction stir welding parameters on the microstructure and mechanical properties of the dissimilar $\mathrm{Al}-\mathrm{Cu}$ joints. Materials Sci. and Eng., 528, 4683-4689.

12. Saeida, T. Abdollah-Zadehb, A., Sazgarib, B. (2010) Weldability and mechanical properties of dissimilar aluminum-copper lap joints made by friction stir welding. J. Alloys and Compounds, 490, 652-655.

13. Makrushin, A.A., Kuklev, A.V., Ajzin, Yu.M. et al. (2005) Radial slab mould with slot channels and nickel coating of walls, 38-41. Moscow: Metallurgizdat.

14. Grigorenko, G.M., Zelenin, V.I., Kavunenko, P.M. et al. (2012) To problem of hardening of mould copper walls of MCCB. In: Rock cutting and metal-working tool: Technique, technology of its manufacturing and application. Issue 15, 548-552. Kiev: Logos.

Received 10.04.2015 